\title{
Determinantes Socioeconômicos e Territoriais da Decisão entre Estudo e Trabalho dos Jovens no Estado de Minas Gerais
}

\author{
Luiz Eduardo de Vasconcelos Rocha ${ }^{1} \mid$ Henrique Eustáquio de Souza ${ }^{2}$ \\ ${ }^{1}$ Universidade Federal de São João del-Rei. E-mail: levrocha@ufsj.edu.br \\ 2 Universidade Federal de São João del-Rei. E-mail: henri14sousa@gmail.com
}

\begin{abstract}
RESUMO
Este artigo analisa, através da metodologia logit multinomial, a influência, no ano de 2010, das características socioeconômicas e territoriais na decisão dos jovens com idades entre 15 e 25 anos entre estudo e trabalho. Os resultados das estimações evidenciaram que a transição dos jovens para a vida adulta, caracterizada pela busca de autonomia diante dos seus familiares, por meio do ganho de capital humano e do acesso ao mercado de trabalho, é marcada pela desigualdade de oportunidades.
\end{abstract}

\section{PALAVRAS-CHAVE}

Mercado de trabalho, Territórios urbano e rural, Desigualdade de renda, Modelo logit multinomial

Socioeconomic and Territorial Determinants of the Decision Between Study and Work of Young People in the State of Minas Gerais

\section{ABSTRACT}

The article analyzes, through the multinomial logit methodology, the influence of socioeconomic and territorial characteristics in the decision of young people, aged between 15 and 25 years, between study and work in 2010. The results of the estimates show that, in the state, the transition from young to adult, characterized by the search for autonomy towards their families through the gain of human capital and access to the labor market, is marked by the inequality of opportunities.

\section{KEYWORDS}

Labor market, Urban and rural territories, Income inequality, Multinomial logit model

\section{CLASSIFICAÇÃO JEL J64, O54, D19}

\section{Introdução}

Neste estudo, teve-se como objetivo analisar os determinantes socioeconômicos e territoriais que influenciam as decisões dos jovens entre estudar e trabalhar no estado de Minas Gerais no ano de $2010^{1}$. O tema é de grande relevância para países como o

\footnotetext{
${ }^{1}$ Há duas justificativas para a realização do estudo no ano de 2010. A primeira é que, ao analisar os determinantes das decisões dos jovens, adotando metodologia alternativa na definição dos territórios rural e urbano no estado, a fonte de dados mais recente é o Censo Demográfico de 2010. A segunda justificativa trata-se da conjuntura socioeconômica desse período, a qual condicionou as decisões dos
} 
Brasil, que passa por transição demográfica e onde os jovens são partes significativas da população. A juventude, que pode ser definida por diversos conceitos, representa, na verdade, a transição da infância para a vida adulta, em que o indivíduo abandona o status de crianças, as quais são totalmente dependentes de seus pais, e vislumbra sua autonomia perante seus familiares (Tomás, 2006). Essa transição, dependendo da forma como se processa, pode definir a constituição da sociedade no presente e apresentar considerável papel na busca do desenvolvimento econômico do país no futuro. "As profundas mudanças verificadas recentemente no mercado de trabalho, em que os avanços tecnológicos têm levado à automatização dos processos produtivos e à precarização das relações de trabalho, direcionaram as atenções, tanto de pesquisadores quanto de formuladores de políticas públicas, para a compreensão dos condicionantes das escolhas que determinam a inserção dos jovens no mercado de trabalho e para a constatação do aumento dos jovens que não estudam e não trabalham, denominados de nem-nem² ${ }^{2}$ Segundo o Censo demográfico de 2010 (IBGE - Instituto Brasileiro de Geografia e Estatística, 2012) e utilizando o conceito mais amplo de trabalho, que incorpora as ocupações não remuneradas, do total de jovens entre 15 e 25 anos no estado, 729.648, ou seja, 19,7\%, dos jovens encontravam-se em situação de vulnerabilidade, não estudando e nem trabalhando; $1.004 .121(27,2 \%)$ apenas estudavam; 546.171, representando $14,8 \%$ do total, conciliavam o estudo com o trabalho; e, finalmente, 1.417 .980 jovens $(38,3 \%)$ apenas trabalhavam.

Neste contexto de profundas mudanças no mercado de trabalho, Novella et al. (2018), coordenaram um vultoso projeto de pesquisa, utilizando como amostra a situação de mais de 15 mil jovens, entre 15 e 24 anos, de nove países da América Latina e do Caribe (Brasil, Chile, Colômbia, El Salvador, Haiti, México, Paraguai, Peru e Uruguai), onde procuram compreender a razões que pesam na escolha entre o trabalho e o estudo na região. Segundo os resultados da pesquisa, $41 \%$ dos jovens na região se dedicam apenas aos estudos, $21 \%$ apenas trabalham, $17 \%$ realizam ambas as duas atividades e $21 \%$ se encontram na categoria nem-nem, percentual bem próximo ao observado no estado de Minas Gerais. Apesar de os países apresentarem diferentes níveis de anos de estudos para os jovens, o aproveitamento, em geral, foi insuficiente no PISA, em que 40\% dos entrevistados demonstraram incapacidade de realizar simples cálculos matemáticos e carência de habilidades técnicas para ingressar no novo mercado de trabalho. Com relação aos jovens nem-nem, verificou-se uma marcante diferença de gênero, enquanto boa parte dos homens procuravam emprego, a maioria das mulheres se dedicava ao trabalho doméstico e ao cuidado de algum membro da família. ${ }^{3}$

jovens, caracterizada, no estado e no país, pela consistente queda da desigualdade de renda e pelo alto crescimento econômico, com o mercado de trabalho próximo do pleno emprego, elevando os rendimentos do trabalho, principalmente no setor de serviços. E, devido às políticas públicas implementadas nas últimas décadas, observou-se também nesse período a elevação da oferta de vagas em todos os níveis de ensino. Para maiores informações sobre as características socioeconômicas do estado de Minas Gerais, ver Oliveira e Siqueira (2010).

${ }^{2}$ Esse termo na literatura inglesa é representado por NEETs (not in education, employment, or training), e na espanhola por NiNis (jóvenes que ni estudian, ni trabajan).

${ }^{3}$ Novella et al. (2018) demonstram que, apesar das diferenças institucionais e socioeconômicas entre os 
Corseuil et al. (2001) realizaram um estudo comparativo em quatro países latinoamericanos (Brasil, Chile, Peru e Honduras), estimando, através do modelo logit multinomial, a influência das características socioeconômicas na decisão dos jovens entre o estudo e o trabalho. Em síntese, esses autores ressaltam como mais relevante, para todos os países, o papel da educação dos pais na probabilidade de os jovens estudarem, acompanhados ou não do trabalho. Outros fatores, como grau de urbanização e número de crianças e de idosos nos domicílios, mostraram-se relevantes. Entretanto, os efeitos dessas variáveis são condicionados pelo gênero e pelo país considerado, o que leva aqueles autores à conclusão de que fatores institucionais e culturais influenciam na decisão dos jovens.

Ao analisarem para o Brasil a trajetória dos jovens nem-nem no período entre 1992 e 2012, Costa e Ulyssea (2014) observaram tendência de queda contínua desse grupo até 2009. Entretanto, entre 2009 e 2012, a proporção aumentou consideravelmente, chegando em 2012 a representar 15,5\% dos jovens entre 15 e 29 anos de acordo com a Pesquisa Nacional por Amostra de Domicílios (PNAD), do Instituto Brasileiro de Geografia e Estatística (IBGE). Segundo os autores, a tendência de queda dos jovens nem-nem se deveu ao aumento da inserção das mulheres, principalmente com filhos, tanto no mercado de trabalho quanto na escola. Por sua vez, a reversão dessa tendência, entre 2009 e 2012, ocorreu simultaneamente para homens e mulheres, sendo mais marcante para os indivíduos de baixa renda, menos escolarizados e residentes no meio rural. Camarano e Kanso (2012) e Monteiro (2013) demonstram também que a propensão de o jovem ser nem-nem está diretamente relacionada às características de ser mulher, ter filhos, possuir baixa educação e possuir reduzida renda domiciliar.

Outro importante estudo para o Brasil, utilizando a base de dados da PNAD de 2011, realizado por Tillmann e Comim (2016), investiga os determinantes das decisões dos jovens entre estudar e trabalhar, adotando, para tanto, duas definições de trabalho: uma mais restrita, que assume como trabalhador apenas aqueles indivíduos que recebem remuneração; e outra mais ampla, incluindo na definição as atividades sem remuneração, entre elas, as atividades domésticas. Os autores, ao compararem os fatores determinantes das escolhas dos jovens para as duas definições de trabalho, verificaram que para a definição mais abrangente as características estar casada e residir no meio rural aumentam as chances de os jovens serem nem-nem, enquanto a maternidade eleva a probabilidade de as jovens apenas trabalharem.

Finalmente, Costa et al. (2013) analisam no Brasil, através do modelo probit bivariado, o efeito de políticas públicas que buscam aumentar a renda per capita familiar sobre a escolaridade dos jovens. Os resultados apontaram que o aumento da renda per capita domiciliar apresentou impacto importante sobre a escolha dos jovens, prin-

nove países analisados, a prioridade das políticas públicas deve ser investir nos jovens visando reverter as altas taxas de desemprego e de informalidade que resultam em um conjunto de condutas de riscos, tais como gravidez precoce, gangues de jovens e criminalidade. Investir nos jovens, segundo os autores, não traria benefícios apenas para esse grupo da população, mas seria condição fundamental para viabilizar o desenvolvimento econômico, a coesão social e o bem-estar dessas nações. 
cipalmente no meio rural, elevando a chance de os jovens estudarem. Os jovens de famílias pobres demonstraram maior probabilidade de entrar no mercado de trabalho precocemente.

Esses trabalhos citados, cada qual com objetivos distintos e análises empíricas para regiões específicas, apresentam em comum as hipóteses de que as características socioeconômicas, demográficas e territoriais marcadas por diferenças institucionais e culturais determinam as decisões dos jovens entre o estudo e o trabalho, a partir dos modelos probit e logit, estimam a contribuição dessas variáveis nas decisões familiares.

Neste artigo, seguindo essa mesma abordagem, teve-se a pretensão de analisar as características que determinam a escolha dos jovens, com idades entre 15 e 25 anos, entre estudar e trabalhar, no estado de Minas Gerais no ano de 2010. Para isso, utilizou-se, de forma similar, a seleção de variáveis dos trabalhos citados, que procuram representar as características socioeconômicas, demográficas e territoriais. Entretanto, na seleção dessas variáveis, propõem-se, no intuito de aprofundar o estudo do tema, algumas contribuições. A primeira refere-se à delimitação do gênero, que geralmente é utilizada de forma isolada na caracterização do jovem. Nesta pesquisa, essa caracterização está atrelada à posição do jovem no domicílio, o que permite delimitar as diferenças, por exemplo, das decisões dos filhos, dos cônjuges e dos chefes dos domicílios, segundo o sexo do jovem.

A segunda contribuição tem como intuito analisar a influência da renda per capita domiciliar na escolha dos jovens. Neste estudo, diferente dos demais, incorpora-se na análise a estrutura da distribuição da renda per capita líquida domiciliar dos jovens. Essa definição considera a renda per capita domiciliar do jovem, subtraindo, caso esse exerça alguma atividade com retorno monetário, sua renda proveniente do trabalho da renda total do domicílio. A renda per capita líquida se constitui um importante parâmetro na decisão do jovem, em uma perspectiva intertemporal, em optar por trabalhar, acompanhado ou não dos estudos. Tal procedimento, além de permitir análise mais ampla dos efeitos da renda domiciliar nas influências das decisões dos jovens ao longo da distribuição, possibilita fazer algumas inferências sobre a relação da pobreza com as escolhas dos jovens estudarem e trabalharem.

A terceira contribuição refere-se à delimitação territorial dos espaços rural e urbano. A localização territorial dos domicílios, segundo vários estudos, exerce forte influência nas decisões dos jovens entre estudo e trabalho ${ }^{4}$. Entretanto, essas pesquisas, realizadas para o caso brasileiro, utilizam a definição oficial que leva em conside-

\footnotetext{
${ }^{4}$ Entre a vasta literatura, destaca-se o artigo de Alcázar et al. (2002), que analisa os determinantes da frequência escolar e do trabalho de jovens em dez países da América Latina, entre eles o Brasil. Os autores constatam, em consonância com a maioria dos trabalhos que aborda o tema para o Brasil, que o território tem grande influência nas decisões dos jovens, sendo desfavorável à região rural. Fatores como renda familiar mais baixa, menor educação dos pais, alto custo de oportunidade do estudo e, pelo lado da oferta, escassez da infraestrutura escolar, entre outros fatores, levam os jovens rurais a trabalharem mais cedo, abandonando os estudos, resultando para a região em um ciclo intergeracional vicioso.
} 
ração apenas o critério da delimitação administrativa. Nesta pesquisa, utilizou-se um critério mais amplo, que, além do administrativo, leva em conta o contingente populacional e a densidade demográfica, o que permite definição mais ampla de território, desagregando as áreas urbanas em cidades rurais, pequenas, médias e grandes.

Este artigo, além desta introdução, é constituído por mais quatro seções. A próxima seção apresenta o referencial teórico da pesquisa; a terceira, a especificação econométrica do modelo logit multinomial, a fonte dos dados e as variáveis explicativas do modelo; a quarta, os resultados e algumas discussões; finalmente, a quinta seção apresenta os comentários finais.

\section{Referencial teórico}

Nesta seção, são descritas a teoria do capital humano, a definição demográfica de jovens e a delimitação dos territórios rural e urbano.

\subsection{Teoria do capital humano e definição demográfica de jovens}

Os estudos que procuram analisar a influência das características socioeconômicas das famílias nas decisões de seus membros entre trabalho e estudo utilizam, em sua grande maioria, a fundamentação teórica do capital humano proposta por Becker (1993). E, quando esses trabalhos são desenvolvidos para um grupo demográfico específico, no caso deste estudo os jovens, torna-se necessário fundamentar a definição desse grupo pelas características pré-determinadas ou pela delimitação etária. A fundamentação teórica da definição da juventude é apresentada detalhadamente, em toda a sua complexidade, por Camarano et al. (2004), Sposito (2000) e Casal et al. (1988).

Na teoria do capital humano, as famílias são consideradas unidades de decisão, em que em uma perspectiva intertemporal, buscam a maximização da utilidade a partir do consumo de serviços, bens e lazer, sujeitos às restrições de tempo e renda ${ }^{5}$. O tempo deve ser alocado entre trabalho, estudo e lazer. Nesse sentido, a decisão da família, condicionada por características socioeconômicas, demográficas e territoriais, tem papel fundamental na decisão do jovem entre estudo e trabalho e, por consequência, no seu futuro. As escolhas das famílias, considerando que a educação é investimento e apresenta um custo no presente e que renderá benefícios no futuro, proporcionam, além de outros benefícios sociais, a inserção no mercado de trabalho com maiores retornos.

\footnotetext{
${ }^{5}$ Segundo Fernandes (2008), a aplicação desse arcabouço para o contexto familiar, denominado modelo unitário, resulta em funções de demanda por consumo e lazer para toda a família. Desse modo, o modelo preocupa-se apenas com as decisões entre as famílias e não leva em consideração como os recursos são distribuídos no âmbito interno dos domicílios. Um modelo alternativo para a decisão de escolha entre estudo e trabalho é o modelo coletivo, esse processo de tomada de decisão ocorre por meio da barganha entre todos os membros da família, sendo, desse modo, geradas várias funções de utilidade para cada membro.
} 
Os trabalhos que têm como objeto de análise a juventude deparam-se inicialmente com a dificuldade de delimitar esse grupo demográfico. Essa delimitação pode seguir características predeterminadas dos indivíduos, como nível educacional e posição no mercado de trabalho e na família, entre outras, ou, a priori, a delimitação de uma faixa etária. Relacionada com a última proposição, segundo Camarano et al. (2004), em 1985, a assembleia da ONU definiu como jovens as pessoas com idades entre 15 e 24 anos. A justificativa para essa delimitação é que a idade de entrada no grupo coincide com o período em que as funções sexuais e reprodutivas já estão desenvolvidas, o que determina uma dinâmica física e psicológica distinta das crianças. E a idade de saída, caracterizada pela transição para a vida adulta, diz respeito ao momento em que os indivíduos finalizam a educação formal, ingressam no mercado de trabalho e constituem a própria família.

Essa definição dos jovens a partir de uma faixa etária, utilizada neste trabalho, se por um lado facilita a operacionalização de pesquisas empíricas, por outro deve levar em conta certo grau de arbitrariedade na definição, à medida que há considerável heterogeneidade no grupo de indivíduos entre 15 e 24 anos de idade. Além disso, devem-se levar em conta as diferentes influências da posição social da família, origem, raça, sexo e região, na forma como se processa a transição dos indivíduos para a vida adulta. Como ressaltam Camarano et al. (2004), a transição dos jovens para a vida adulta é influenciada pelas características pessoais e pelas oportunidades propiciadas pela família, sendo essas influências condicionadas pelo contexto social e pelas políticas públicas. Dentro dessa perspectiva, este estudo, assumindo a heterogeneidade no grupo de jovens entre 15 e 25 anos de idade, pretende analisar justamente como que características socioeconômicas e territoriais influenciam a decisão dos jovens pela opção entre estudo e trabalho no estado de Minas Gerais, decisão essa determinante na transição para a vida adulta ${ }^{6}$.

\subsection{Delimitação dos territórios rural e urbano}

Estudos que se propõem, como este, a utilizar a delimitação territorial na caracterização ocupacional dos jovens se deparam com os problemas teóricos e, principalmente, empíricos na definição acerca de o que é rural e urbano. De forma geral, essa definição está associada a duas linhas teóricas: a dicotômica e a de continuum. A primeira ressalta as diferenças ou os contrastes entre esses dois espaços, sendo o território rural pensado como algo que se opõe ao urbano. Na segunda linha, ao contrário, verifica-se uma aproximação da realidade desses dois espaços (Bertrand, 1973).

Segundo Reis (2006), as características empíricas que colocam as regiões em polos opostos, levantadas por Sorokin et al. (1929), são referentes, em contraste com

\footnotetext{
${ }^{6}$ IBGE - Instituto Brasileiro de Geografia e Estatística (2017) descreve um quadro abrangente das condições de vida da população brasileira, considerando diferentes desagregações territoriais e grupos populacionais específicos, entre eles a população jovem.
} 
o setor urbano, às regiões rurais que apresentam ocupações concentradas na agricultura. Com isso, grande parte da sua composição territorial ainda se encontra intacta em relação à exploração econômica, com reduzidas densidades demográficas e, consequentemente, com população com características mais homogêneas, tendo em vista a pequena divisão do trabalho voltada quase que exclusivamente para as atividades agrícolas. Entretanto, as profundas transformações socioespaciais observadas ao longo do século XX, caracterizadas pelo crescimento das cidades, pela industrialização da agricultura e pelo transbordamento do urbano nas áreas rurais, verificados de forma marcante também no Brasil, levaram a uma nova interpretação das definições territoriais. Com isso, a visão dicotômica passa a dar lugar à interpretação teórica do espaço continuum, em que a polarização antagônica é substituída por um complexo gradiente de variações espaciais.

No Brasil, diante das mudanças ambientais, econômicas e sociais, mais intensas a partir da década de 1980, observaram-se a elevação da urbanização do campo e o surgimento de dinâmicas espaciais apontando para uma nova ruralidade, caracterizada, segundo Grossi e Silva (2002), pela coexistência de três grupos de atividades, quais sejam: a agropecuária moderna, ligada à agroindústria e à produção de commodities; um grupo de novas atividades agrícolas, ligado a nichos especiais de mercado, como a produção de culturas orgânicas; e um conjunto de atividades não agrícolas, ligado à moradia, ao lazer e à prestação de serviços. Entretanto, a despeito dessas profundas mudanças, o Brasil, do ponto de vista da legislação que define os espaços territoriais, segue a legislação da época do Estado Novo (Decreto-Lei no 311, de 1938), que considera como espaço urbano toda a sede de municípios e distritos, sem levar em consideração suas características funcionais e estruturais.

Segundo Veiga (2002), essa inadequação da legislação com a realidade complexa da nova ruralidade no Brasil tem levado a uma série de problemas relacionados à definição e análise da configuração territorial, dificultando a formulação de políticas públicas de combate à pobreza, de distribuição de renda e de desenvolvimento rural. Nesse sentido, visando evitar os equívocos impostos pela norma legal, esse autor propõe, a partir da base de dados censitários do país, uma nova delimitação dos espaços rural e urbano, combinando o critério do tamanho populacional do município com a densidade demográfica e a sua localização. Este estudo, ao adotar essa delimitação proposta e fugindo da simplificação da legislação atual não mais condizente com a realidade, divide o estado de Minas Gerais em cinco tipologias territoriais: rural, cidade rural, cidade pequena, cidade média e cidade grande ${ }^{7}$.

\footnotetext{
${ }^{7}$ Maia e Buainain (2015), assumindo a complexidade na delimitação dos territórios rurais, mapearam a população rural brasileira, utilizando como fonte de dados os últimos três Censos Demográficos. Uma das principais constatações do estudo, em decorrência do processo de urbanização intensificado na década de 1970, foi o significativo decréscimo da população rural. Ainda assim, os autores afirmam que, em termos absolutos, a população rural brasileira totalizava 30 milhões de pessoas em 2010, contingente esse superior à população de praticamente todos os países da América Latina, exceto a Argentina.
} 


\section{Metodologia}

Nesta seção, são descritas a especificação econométrica do modelo logit multinomial, a fonte e as características dos dados secundários da pesquisa.

\subsection{Modelo econométrico - logit multinomial}

Os modelos que utilizam como variáveis dependentes decisões qualitativas devem levar em conta como essas escolhas são feitas. Quando as decisões são tomadas de maneira independente, o modelo mais adequado é o probit bivariado. Já para decisões sequenciais, o mais utilizado é o probit sequencial, enquanto, finalmente, no caso desta pesquisa, em que as escolhas entre o trabalho e os estudos dos jovens ocorrem simultaneamente, o mais indicado é o modelo logit multinomial.

Para esse modelo, a probabilidade de escolha das famílias pode ser apresentada pela seguinte equação:

$$
P\left(Y_{i}=j \vee w_{i}\right)=\frac{\exp \left(w_{i} \alpha_{j}\right)}{\sum_{k=0}^{j} \exp \left(w_{i} \alpha_{j}\right)}, j=0,1, \ldots, m
$$

em que $P_{j}$ representa a probabilidade de uma familia $i$ optar pela escolha $j, Y_{i}$ é a variável aleatória que indica a escolha da família, $w$ é a matriz de características dos indivíduos e $\alpha$ é o vetor dos parâmetros a serem estimados. Segundo Greene (2012), essa equação estimada apresenta um conjunto de probabilidades para as $j$ escolhas (categorias) dos individuos de acordo com as suas características $w_{i}$, representadas no trabalho pelas condições internas e externas do domicílio. Entretanto, a especificação do modelo segundo a equação (1) gera uma indeterminação. Para contornar esse problema, deve ser feita uma normalização, em que uma alternativa é definida como referência. Nesta pesquisa, há quatro possiveis escolhas a serem tomadas em função da interação de duas situações, quais sejam: $e^{i}=1$, se o jovem $i$ estuda; 0 , se não estuda; $t^{i}=1$, se o jovem $i$ trabalha; 0 se não trabalha. Neste caso:

$$
Y_{i=} \mid \begin{aligned}
& 0 \text { se } e^{i}=0 \text { e } t^{i}=1 \text { (não estuda e trabalha - NET) } \\
& 1 \text { se } e^{i}=0 \text { e } t^{i}=0 \text { (não estuda e não trabalha - NENT) } \\
& 2 \text { se } e^{i}=1 \text { e } t^{i}=0 \text { (estuda e não trabalha - ENT) } \\
& 3 \text { se } e^{i}=1 \text { e } t^{i}=1 \text { (estuda e trabalha - ET) }
\end{aligned}
$$

Nessas quatro possibilidades de escolhas, o modelo logit multinomial, normalizando a 0 (não estuda e trabalha), será estimado a partir de três equações: uma para a escolha 1 (não estudar e não trabalhar), uma para a 2 (estuda e não trabalha) e uma para a 3 (estuda e trabalhar). Neste caso, as probabilidades seriam representadas pela equação a seguir: 


$$
\operatorname{Prob}\left(Y_{i}=j \vee w_{i}\right)=P_{i j}=\frac{\exp \left(w_{i} \alpha_{j}\right)}{1+\sum_{k=0}^{j} \exp \left(w_{i} \alpha_{k}\right)}, j=0,1, \ldots, m
$$

Ao contrário do método dos mínimos quadrados ordinários, nos modelos de probabilidade, os coeficientes estimados das variáveis explicativas sobre a variável dependente não representam diretamente as respostas marginais. Assim, esses efeitos marginais são obtidos a partir da diferenciação da equação 2 e representados pela equação 3.

$$
\frac{\partial P_{i j}}{\partial w_{i}}=P_{i j}\left[\alpha_{j}-\sum_{k=0}^{j} P_{i k} \alpha_{k}\right]=P_{i j}\left[\alpha_{j}-\bar{\alpha}\right]
$$

Segundo Araújo (2010), os efeitos marginais não apresentam necessariamente o mesmo sinal dos coeficientes estimados. Para as variáveis independentes binárias, o efeito marginal demonstra a variação da probabilidade do acontecimento $j$ entre dois grupos considerados. No caso das variáveis contínuas, o efeito marginal é a variação da probabilidade de ocorrência de um evento $j$, em resposta ao aumento do valor da variável independente, avaliado a partir do seu ponto médio.

Para aprofundar o conhecimento da influência das variáveis explicativas nas decisões dos jovens entre o trabalho e o estudo, além dos seus efeitos marginais, podem ser realizadas simulações do impacto de algumas dessas características, considerando as diferenças territoriais, sobre a probabilidade de ocorrência dessas escolhas. Tais simulações, segundo Oliveira et al. (2009), são feitas a partir da substituição dos valores de cada variável explicativa de interesse em cada uma das estimações, gerando uma probabilidade de ocorrência do estado $j$ para cada indivíduo $i$, em dado território, que é diferente para cada valor da variável explicativa. A título de exemplo, pode-se utilizar a variável estrutura da distribuição da renda per capita domiciliar que deverá assumir os valores de 1 a 10, que representam os décimos da distribuição. Assim, inicialmente, para todos os indivíduos da amostra, substitui-se o valor da variável pelo valor 1, considerando que todos esses indivíduos residem no território rural, recalculando as probabilidades de cada estado da natureza para cada indivíduo. A partir desse procedimento, têm-se as probabilidades preditas para cada escolha das famílias considerando que todos os jovens residem em domicílios com renda per capita no primeiro décimo da distribuição e moram no meio rural. Posteriormente, refazem-se os cálculos para os demais valores da variável, de 2 até 10, incluindo todos no processo de simulação. Tal procedimento poderá ser replicado para as demais regiões urbanas.

Segundo Escolano e Pazello (2014), a simulação pode ser apresentada no seu formato generalizado, em que $w^{0}$ é a variável explicativa de interesse, sendo $w_{1}^{0}$ o primeiro valor que ela pode assumir. Assim, tem-se a equação 4, ignorando o subscrito i. 


$$
\hat{p}_{j}^{w_{1}^{0}}=A\left(w^{0}, w^{-0}, \hat{\alpha}\right)=\frac{\exp \left(w^{-0} \hat{\alpha}_{j}^{-0}+w_{1}^{0} \hat{\alpha}_{j}^{0}\right)}{\sum_{l=1}^{m} \exp \left(w^{\prime} \hat{\alpha}_{j}\right)}
$$

em que $w^{-0}$ representa os outros regressores, exceto $w^{0} ; \hat{\alpha}_{j}^{-0}$ é o vetor de coeficientes estimados das variáveis explicativas $w^{-0}$ e $\hat{\alpha}_{j}^{0}$ representa o coeficiente da variável $w^{0}$ no estado j. Para a visualização dos dados, utiliza-se a média para todos os jovens de $\hat{p}_{j}^{w_{1}^{0}}$. Essa é a probabilidade esperada para o estado $j$ caso $w^{0}=w^{-0}$ :

$$
\hat{p}_{j}^{w_{1}^{0}}=\frac{1}{n} \sum_{i=1}^{n} \hat{p}_{j}^{w_{1}^{0}}
$$

Seguindo esses mesmos procedimentos para os demais valores que $w^{0}$ pode assumir, torna-se possível encontrar a probabilidade para cada um dos casos. E isso possibilita a construção de gráficos nos quais as relações entre os valores assumidos pelas variáveis explicativas e as probabilidades associadas às escolhas dos jovens podem ser comparadas e analisadas.

\subsection{Fonte dos dados e caracterização das variáveis explicativas}

Nesta pesquisa, utilizaram-se como fonte a amostra dos microdados do Censo Demográfico de 2010 (IBGE - Instituto Brasileiro de Geografia e Estatística, 2012) e o conceito de trabalho amplo, que incorpora as ocupações não remuneradas. Em Minas Gerais, nesse ano, a amostra de jovens entre 15 e 25 anos de idade é constituída de 472.821 indivíduos, representando, a partir do fator de expansão, o universo de 3.697.923 jovens. Desse total, segundo a escolha entre estudo e trabalho, 729.648 jovens, ou seja, 19,7\%, encontravam-se em situação de vulnerabilidade, não exercendo nenhuma atividade (NENT); 1.004.121 (27,2\%) apenas estudavam (ENT); 546.171, representando $14,8 \%$ do total, conciliavam o estudo com o trabalho (ET); e, finalmente, 1.417 .980 jovens $(38,3 \%)$ apenas trabalhavam (NET).

Na estimação do modelo econométrico logit multinomial, em que se pretendem analisar os determinantes da escolha dos jovens no estado de Minas Gerais, as variáveis explicativas, utilizadas nos cálculos das probabilidades, descritas no Quadro $1^{8}$, dividem-se em três grupos: o dos fatores caracterizados pelas informações dos indivíduos; o das características dos domicílios; e o da localização territorial.

\footnotetext{
${ }^{8}$ No apêndice, estão descritos os procedimentos metodológicos, indicando o código das variáveis dos microdados, utilizadas na definição da amostra dos jovens, das escolhas entre estudo e trabalho e das variáveis explicativas do modelo econométrico, descritas no Guadro A1.
} 


\section{Quadro 1. Variáveis explicativas utilizadas na estimação econométrica}

\begin{tabular}{ll}
\hline \hline Variável & Descrição \\
\hline Atributos pessoais & Variável contínua que indica a idade dos jovens entre 15 e 25 anos. \\
Idade & Variável dummy: 1 branco; 0 não branco*. \\
Branco & Variável dummy que assume valor 1 para os jovens que possuem ensino \\
Ensino primário & fundamental incompleto ou sem instrução*e 0 caso contrário. \\
& Variável dummy que assume valor 1 para os jovens que possuem ensino \\
Ensino fundamental & fundamental completo ou médio incompleto e 0 caso contrário*. \\
& Variável dummy que assume valor 1 para os jovens que possuem ensino \\
Ensino médio & médio completo ou superior incompleto e 0 caso contrário*. \\
& Variável dummy que assume valor 1 para os jovens que possuem ensino \\
Ensino superior & superior completo e 0 caso contrário*.
\end{tabular}

Domicílio

Número de pessoas

10 décimo da renda per capita

20 ao 100 décimo da renda per capita

Não responsável

Responsável pelo domicílio - homem

Responsável pelo domicílio - mulher

Não cônjuge

Cônjuge - homem

Cônjuge - mulher

Não filho, enteado e neto

Filho, enteado e neto - homem

Filho, enteado e neto - mulher

Residência

Território rural

Cidade rural

Cidade pequena

Cidade média

Variável contínua que indica o total de pessoas residentes no domicílio.

Variável dummy igual a 1 para os jovens com renda per capita domiciliar no primeiro décimo da distribuição* e 0 caso contrário.

Variável dummy igual a 1 para os jovens com renda per capita domiciliar no décimo da distribuição e 0 caso contrário*.

Variável dummy que assume valor 1 para os jovens não responsáveis pelo domicílio* e 0 caso contrário.

Variável dummy que assume valor 1 para os jovens homens responsáveis pelo domicílio e 0 caso contrário*.

Variável dummy que assume valor 1 para os jovens mulheres responsáveis pelo domicílio e 0 caso contrário*.

Variável dummy que assume valor 1 para os jovens na condição de não cônjuge* e 0 caso contrário.

Variável dummy que assume valor 1 para os jovens homens na condição de cônjuge e 0 caso contrário*.

Variável dummy que assume valor 1 para os jovens mulheres na condição de não cônjuge e 0 caso contrário*.

Variável dummy 1 para os jovens que não estiverem na condição de filho, enteado e neto no domicílio* e 0 caso contrário.

Variável dummy 1 para os jovens homens na condição de filho, enteado e neto no domicílio e 0 caso contrário*.

Variável dummy 1 para as jovens mulheres na condição de filha, enteada e neta no domicílio e 0 caso contrário*.

Variável dummy que assume valor 1 para jovens residentes no território rural* e 0 caso contrário.

Variável dummy que assume valor 1 para jovens residentes em cidades rurais e 0 caso contrário*.

Variável dummy que assume valor 1 para jovens residentes em cidades pequenas e 0 caso contrário*.

Variável dummy que assume valor 1 para jovens residentes em cidades médias e 0 caso contrário*.

Variável dummy que assume valor 1 para jovens residentes

Cidade grande em cidades grandes e 0 caso contrário*.

Fonte: Elaboracão própria a partir dos dados do Censo de 2010

Nota: * Elaboracãa própria a partir dos da degoria de referência/controle. 
Considerando as características individuais dos jovens, o efeito esperado da idade, levando em conta que esse período trata da transição para a vida adulta, tende a ser positivo sobre a probabilidade de o jovem exercer alguma atividade laboral e negativo no caso de ele estudar. O efeito esperado negativo da idade sobre a probabilidade de os jovens estudarem se deve à grande evasão escolar observada no país na transição do ensino fundamental para o ensino médio e, também, à pouca inserção deles no ensino superior. Para a variável cor, em uma sociedade desigual como a brasileira, na qual ainda predomina a discriminação de raça, espera-se maior probabilidade de os jovens brancos terem maior acesso à educação e maior probabilidade de acesso ao mercado de trabalho em relação aos das demais raças. Na variável nível de instrução educacional, pretende-se analisar como o nivel educacional dos jovens influencia as suas escolhas de continuar a estudar e a ingressar no mercado de trabalho. Em princípio, espera-se que, quanto maior o nível educacional, maior a probabilidade de o jovem exercer alguma atividade laboral; entretanto, a priori, não se pode prever a influência sobre a decisão de continuar nos estudos.

O efeito esperado do número de pessoas no domicílio é negativo para a probabilidade de o jovem estudar e positivo para a ocupação laboral. Famílias numerosas levam os jovens, por necessidade de contribuírem para o sustento dos seus membros, a anteciparem a entrada no mercado de trabalho, levando ao abandono prematuro dos estudos. A estrutura da distribuição da renda é representada pelos décimos da renda domiciliar per capita líquida, originária de todas as fontes. A variável renda, como foi ressaltado anteriormente, apresenta os resultados mais controversos quanto à sua influência sobre a decisão dos jovens. Ao introduzir a análise da estrutura da distribuição, tema pouco abordado na literatura, a priori, não se pode prever o sinal da variável.

As variáveis que representam a posição do jovem no domicílio, condicionada pela relação de gênero, assumem as possíveis situações em que o jovem passa a ser o responsável pelo domicílio, cônjuge ou filho. Nas situações em que o jovem assume a chefia do domicílio ou a condição de cônjuge, característica da vida adulta, esperase maior probabilidade de exercerem alguma atividade laboral e menor probabilidade de alocarem o tempo nos estudos. Resta conhecer a diferença da magnitude dessas probabilidades entre os jovens dos sexos masculino e feminino.

Finalmente, dentro dos fatores explicativos externos que influenciam as escolhas dos jovens, apresenta-se o local de residência. Para a delimitação do território, a pesquisa utilizou metodologia proposta por Ney e Hoffmann (2009), que leva em consideração três critérios: i) delimitação administrativa, definição oficial apresentada nos censos demográficos; ii) contingência populacional; e iii) densidade demográfica. O território rural passa a ser constituído pelas áreas delimitadas pelas administrações oficialmente como "rurais". As "cidades rurais" são aquelas compostas pela população urbana das cidades com menos de 20 mil habitantes e com densidade demográfica menor que 140 habitantes por $\mathrm{km}^{2}$. As "cidades pequenas", com população de até 100 
mil habitantes (as com menos de 20 mil habitantes deverão apresentar densidade demográfica superior a 140 habitantes por $\mathrm{km}^{2}$ ), "cidades médias" com população entre 100 e 299 mil habitantes e as "cidades grandes", com população superior a 300 mil habitantes. Segundo a maioria dos estudos, no território rural, verifica-se maior probabilidade de os jovens trabalharem e não estudarem. Isso ocorre devido à maior informalidade no mercado laboral, prevalência de trabalhos agrícolas familiares e infraestrutura escolar deficiente. Para os demais territórios, a priori, não se pode prever o comportamento dos sinais.

\section{Resultados e discussões}

Nesta seção, inicialmente, é apresentada a análise descritiva das variáveis explicativas do modelo a ser estimado. A seguir, são descritos os resultados da estimação do modelo logit multinomial, os efeitos marginais e, finalmente, a simulação do impacto da estrutura distributiva da renda per capita domiciliar líquida sobre a probabilidade predita das decisões dos jovens entre estudar e trabalhar, considerando-se as diferenças territoriais e a posição do jovem no domicílio.

\subsection{Análise descritiva}

Das variáveis explicativas propostas no modelo econométrico, descritas na Tabela 1, apenas duas, a idade dos jovens e o número de indivíduos residentes no domicílio, são variáveis quantitativas. As estatísticas descritivas dessas variáveis para a população jovem do estado de Minas Gerais demonstram média de idade de 20 anos e desvio-padrão de 3,2 anos e média de 4,4 indivíduos residentes nos domicílios com desvio de 1,8. A Tabela 1 apresenta as estatísticas descritivas para o restante das variáveis qualitativas do modelo proposto, o que demonstra que, do total de 3,69 milhões de jovens no estado, considerando os estratos de alocação do tempo, 38,3\% apenas trabalhavam, 14,8\% conciliavam os estudos com o trabalho, 27,2\% dedicavam o tempo apenas ao estudo e, finalmente, 19,7\% estavam na situação de ociosidade, nem estudando nem trabalhando.

Do total da população de jovens, $41,9 \%$ são da raça branca. Com relação ao nível de instrução, cabe destacar que $28,6 \%$ dos jovens não tinham instrução ou não haviam completado o ensino básico, demonstrando significativo atraso educacional, e apenas 3,8\% possuíam ensino superior completo. A maioria dos jovens, $28,1 \%$, residia nas cidades pequenas do estado, 24,5\% nas cidades grandes, 18,2\% nas médias e $15,3 \%$ e $13,9 \%$, respectivamente, nas cidades rurais e territórios rurais ${ }^{9}$. Finalmente, com relação à posição do jovem no domicílio, 48,2\% de homens e 32,3\% de mulheres estavam na condição de filhos, enteados ou netos. Essa menor proporção de mulheres nessa condição é explicada pela transição mais rápida para a situação

\footnotetext{
${ }^{9}$ Dos 853 municípios do estado, segundo a classificação territorial proposta no trabalho, apenas 6 municípios são considerados como cidades grandes, 23 são cidades médias, 163 são cidades pequenas e 661 municípios, onde residem apenas 15,3\% dos jovens, são classificados como cidades rurais.
} 
de cônjuges, assumindo a proporção de 8,9\%, enquanto os jovens homens são apenas 1,2\%. Na situação de responsável pelo domicílio, como era de se esperar, observa-se uma pequena participação dos jovens, sendo que a dos homens $(6,3 \%)$ foi superior à participação das mulheres $(3,7 \%)$.

Tabela 1. Estatísticas descritivas (frequência e proporção) das variáveis qualitativas utilizadas no modelo logit multinomial

\begin{tabular}{|c|c|c|c|}
\hline & Variáveis & Frequência & Proporção (\%) \\
\hline \multirow{4}{*}{ Alocação do tempo } & NENT & 729.648 & 19,7 \\
\hline & ENT & 1.004 .121 & 27,2 \\
\hline & $\mathrm{ET}$ & 546.171 & 14,8 \\
\hline & NET & 1.417 .980 & 38,3 \\
\hline \multirow{3}{*}{ Raça } & Branca & 1.548 .918 & 41,9 \\
\hline & Negra, parda e amarela & 2.149 .005 & 58,1 \\
\hline & Sem instrução e fund. Incompleto & 1.057 .514 & 28,6 \\
\hline \multirow{3}{*}{ Instrução } & Fund. completo e médio incompleto & 1.253 .904 & 33,9 \\
\hline & Médio completo e superior incompleto & 1.246 .130 & 33,7 \\
\hline & Superior completo & 140.375 & 3,8 \\
\hline $\begin{array}{l}\text { Renda domiciliar } \\
\text { per capita líquida }\end{array}$ & Décimos da distribuição & 369.792 & 10,0 \\
\hline \multirow{5}{*}{ Território } & Rural & 515.672 & 13,9 \\
\hline & Cidade rural & 564.456 & 15,3 \\
\hline & Cidade pequena & 1.037 .990 & 28,1 \\
\hline & Cidade média & 672.052 & 18,2 \\
\hline & Cidade grande & 907.752 & 24,5 \\
\hline \multirow{3}{*}{ Responsável do domicílio } & Homem & 231.360 & 6,3 \\
\hline & Mulher & 135.785 & 3,7 \\
\hline & (Outros) & 3.330 .778 & 90,1 \\
\hline \multirow{3}{*}{ Cônjuge } & Homem & 43.151 & 1,2 \\
\hline & Mulher & 328.728 & 8,9 \\
\hline & (Outros) & 3.326 .044 & 89,9 \\
\hline \multirow{3}{*}{ Filhos, enteados e netos } & Homem & 1.413 .056 & 48,2 \\
\hline & Mulher & 1.195 .754 & 32,3 \\
\hline & (Outros) & 1.089 .113 & 29,5 \\
\hline
\end{tabular}

Fonte: Elaboração própria a partir dos dados do Censo de 2010. 
O modelo econométrico do trabalho se aplica à análise da influência da estrutura distributiva da renda per capita domiciliar líquida sobre a probabilidade predita das decisões dos jovens entre o trabalho e o estudo, considerando as diferenças territoriais e a posição do jovem no domicílio. A partir desse propósito, a Tabela 2 descreve a estrutura das escolhas e a posição da ocupação dos jovens que exerciam alguma atividade laboral, acompanhada ou não dos estudos, segundo os décimos da distribuição da renda líquida per capita domiciliar.

Tabela 2. Decisão entre estudo e trabalho e posição na ocupação dos jovens segundo os décimos da renda domiciliar per capita líquida

\begin{tabular}{|c|c|c|c|c|c|c|c|c|c|c|c|}
\hline \multirow{2}{*}{ Décimos $^{1}$} & \multicolumn{4}{|c|}{ Decisão estudo e trabalho(\%) } & \multicolumn{7}{|c|}{ Posição na ocupação² (\%) } \\
\hline & NENT & ENT & NET & ET & 1 & 2 & 3 & 4 & 5 & 6 & 7 \\
\hline 1) $\mathrm{R} \$ 62,45$ & 26,4 & 20,5 & 44,9 & 8,3 & 49,5 & 2,4 & 30 & 10,5 & 0,3 & 1,2 & 6 \\
\hline 2) $\mathrm{R} \$ 140,00$ & 28,6 & 28,5 & 32,5 & 10,3 & 38,8 & 1,4 & 40,5 & 10,6 & 0,2 & 3 & 5,2 \\
\hline 3) $\mathrm{R} \$ 195,40$ & 25,9 & 26,8 & 35,9 & 11,4 & 46,9 & 1,9 & 36,3 & 9,6 & 0,1 & 1,9 & 2,9 \\
\hline 4) $\mathrm{R} \$ 255,00$ & 22,6 & 27,1 & 37,3 & 12,9 & 50,7 & 1,9 & 33,8 & 9,6 & 0,1 & 1,8 & 1,8 \\
\hline 5) $\mathrm{R} \$ 302,50$ & 20,7 & 23,3 & 42,1 & 13,9 & 55,6 & 2,2 & 29,9 & 9,2 & 0,2 & 1,3 & 1,2 \\
\hline 6) $\mathrm{R} \$ 375,00$ & 18,5 & 25,4 & 41,2 & 14,9 & 57,1 & 2,4 & 28,2 & 9,2 & 0,3 & 1,5 & 1,2 \\
\hline 7) $\mathrm{R} \$ 466,66$ & 15,3 & 25,8 & 42,1 & 16,9 & 60,4 & 2,4 & 25,6 & 8,9 & 0,3 & 1,5 & 0,6 \\
\hline 8) $\mathrm{R} \$ 609,50$ & 14,2 & 26,9 & 40,4 & 18,5 & 62,2 & 2,8 & 22,3 & 9,8 & 0,4 & 1,7 & 0,6 \\
\hline 9) $\mathrm{R} \$ 1.000,00$ & 12,1 & 31,3 & 35,1 & 21,5 & 61,3 & 3,7 & 20,5 & 11,1 & 0,7 & 2 & 0,4 \\
\hline 10) & 10,3 & 41,9 & 25,5 & 22,2 & 53,8 & 5,5 & 20,9 & 14,2 & 2,1 & 3 & 0,3 \\
\hline
\end{tabular}

Fonte: Elaboração própria a partir dos dados do Censo de 2010.

Nota: (1) Décimos, divisão da população jovem em dez grupos, e decis, valor monetário,

em reais de agosto de 2010, que separa os décimos em ordem crescente;

(2) Posição na ocupação: 1- empregado com carteira assinada; 2 - militares

e funcionários públicos; 3 - empregados sem carteira assinada; 4 - conta própria;

5 - empregador; 6 - não remunerado; e 7 - próprio consumo.

Ao analisar os valores monetários dos nove decis, que separam a população em 10 grupos iguais de 369 mil jovens, em ordem crescente da renda per capita líquida, e considerando o seu valor médio de $\mathrm{R} \$ 508,02$, bem acima da mediana de $\mathrm{R} \$ 302,50$, representada pelo quinto decis, pode-se constatar, primeiro, baixa renda líquida per capita para a grande maioria dos jovens; segundo, a alta concentração da renda. Levando em consideração que, na época da coleta dos dados censitários, em agosto de 2010, o salário-mínimo vigente no país era de $\mathrm{R} \$ 510,00$, apenas a partir do oitavo decis foram observados valores acima do salário-mínimo. E, por outro lado, setenta porcento dos jovens tinham renda per capita inferior ao salário-mínimo.

Observa-se nítida influência da estrutura da distribuição da renda na escolha dos 
jovens entre estudar e trabalhar e na posição quanto à sua ocupação. Ao transitarem para os décimos superiores da distribuição, verifica-se decréscimo da proporção de jovens que não estudam nem trabalham (NENT) e também dos que apenas trabalham (NET). Já em sentido contrário, observa-se o aumento da proporção dos que apenas estudam (ENT) ou conciliam o estudo com o trabalho (ET). Em relação à posição da ocupação, para aqueles jovens que trabalham, nota-se a maior proporção em ocupações com carteira de trabalho assinada, empregos públicos e conta própria. Em sintese, os jovens no topo da distribuição estudam mais, o que pode garantir no futuro melhores retornos do trabalho, e esses jovens estão em ocupações mais vantajosas no mercado de trabalho, emprego formal.

\subsection{Resultados da estimação do modelo logit multinomial}

No intuito de aprofundar esta análise, são apresentados, primeiramente, os resultados do modelo logit multinomial, que descreve a probabilidade das escolhas dos jovens entre trabalho e estudo em função do conjunto de características determinantes descritas na seção anterior. Posteriormente, são realizadas simulações do impacto dos décimos da distribuição da renda domiciliar per capita líquida, considerando as diferenças territoriais e a posição do jovem no domicílio, sobre a probabilidade de ocorrência das escolhas entre estudo e trabalho.

Na estimação do logit multinomial para uma amostra de 469.562 observações, consideraram-se as escolhas não estudar nem trabalhar (NENT), estudar e não trabalhar (ENT) e estudar e trabalhar (ET), relativamente à alternativa não estudar e trabalhar (NET), apresentando, em termos globais, um bom ajustamento, tendo em vista que o Pseudo R2 apresentou valor maior que zero, 0,2074. Considerando, ainda, a observação da Prob > chi2 e pelo teste da razão de verossimilhança, cuja hipótese nula é de que todos os coeficientes associados às variáveis explicativas são nulos, pode-se concluir que o modelo é globalmente significativo.

Os dados da Tabela 3 apontam os resultados das estimações dos efeitos marginais nas quatro equações que determinam a escolha dos jovens, calculados a partir do ponto médio das variáveis contínuas e da alteração da situação-base em relação às demais opções para as variáveis dicotômicas, nas quatro equações. Deve-se destacar que a maioria dos coeficientes apresentou significância estatística a 1\%. As estimações indicaram que o aumento de um ano na idade, a partir do seu ponto médio, 20 anos, e considerando tudo o mais constante, elevaria em 1,39 ponto percentual (p.p.) a probabilidade de os jovens não estudarem nem trabalharem e em 7,36 p.p. a de eles apenas trabalharem. Em contrapartida a esses aumentos das probabilidades preditas, tendo em vista que todas as possiveis opções de escolhas dos jovens estão representadas nas quatro equações, observa-se a redução de 7,10 p.p. na probabilidade de esses jovens apenas estudarem e 1,65 p.p. de conciliarem os estudos com o trabalho. 


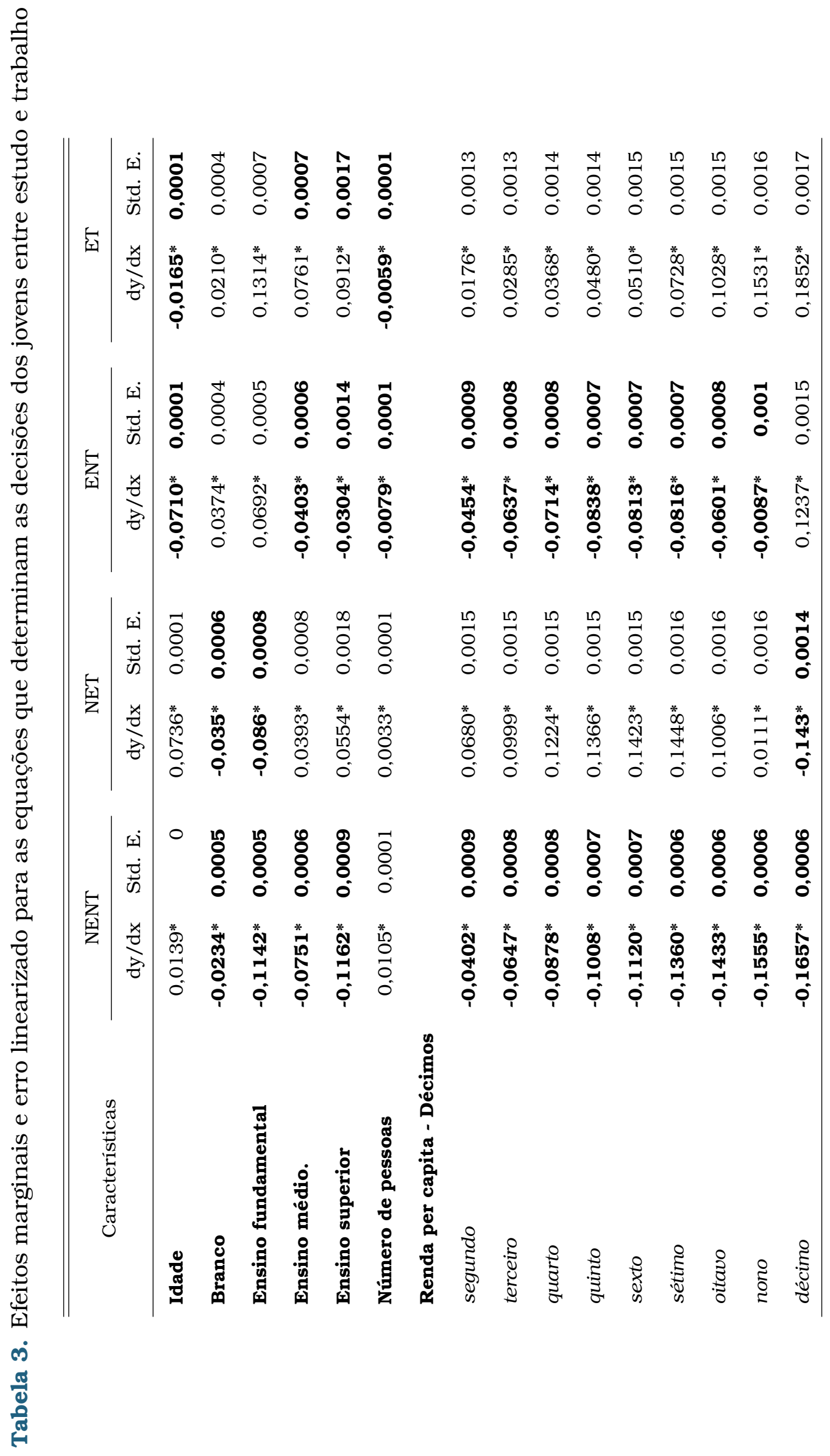




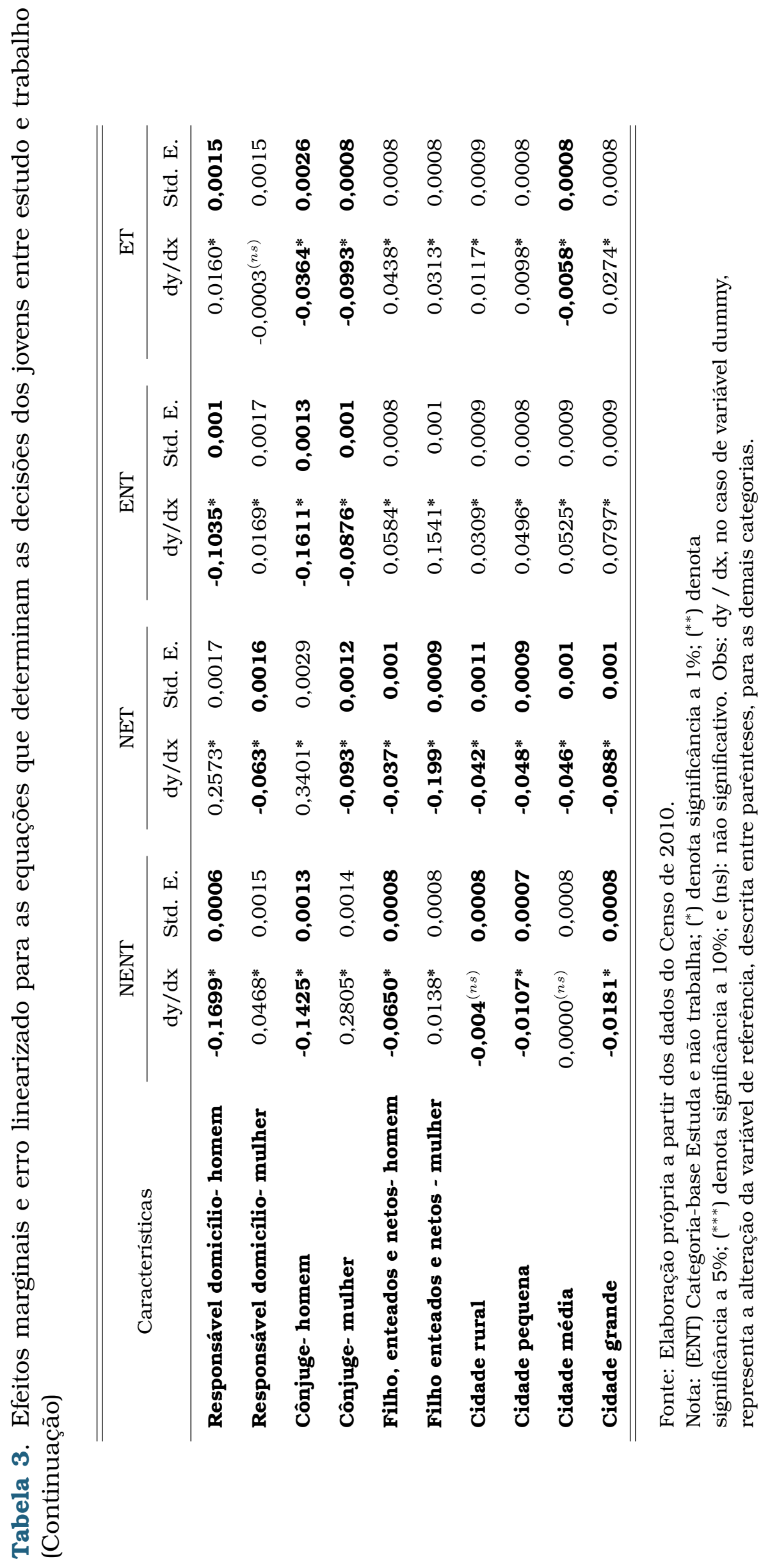


Os resultados indicam que a raça influencia as decisões em favor dos jovens brancos ao aumentar a probabilidade de optarem pelos estudos em relação aos das demais raças. Os jovens brancos, em relação aos das demais raças, apresentam redução de 2,33 p.p. e 3,50 p.p. na probabilidade, respectivamente, de não estudarem nem trabalharem e apenas trabalharem. Entretanto, em contrapartida, elevam a probabilidade de apenas estudarem e conciliarem o estudo com o trabalho em, respectivamente, 3,74 p.p. e 2,10 p.p. O aumento de um indivíduo no número de pessoas no domicílio, em relação à média de 4,4 indivíduos, elevaria a probabilidade predita de os jovens não estudarem nem trabalharem em 1,05 p.p. e apenas trabalharem em 0,33 p.p.. Em contrapartida, a probabilidade predita dos jovens apenas estudarem e conciliarem o estudo com o trabalho reduziria, respectivamente, em 0,79 p.p. e 0,59 p.p..

Os coeficientes das variáveis dummies utilizados para analisar a influência do nível educacional na escolha dos jovens demonstraram que a transição da situação-base, sem instrução e fundamental incompleto, para as demais situações, que representam a elevação do nível educacional, reduziria entre 7,51 p.p. e 11,62 p.p. a probabilidade de os jovens estarem em situação de vulnerabilidade, não estudando nem trabalhando, e, por sua vez, aumentaria a probabilidade, entre 7,61 p.p. e 13,14 p.p., de os jovens conciliarem os estudos com o trabalho ET. A probabilidade predita de os jovens estarem no estrato de alocação apenas trabalhando, considerando a transição da base para situação do jovem com fundamental completo ou médio incompleto, reduziria em 8,6 p.p.; considerando a transição para o ensino médio completo ou o superior incompleto, o efeito seria o contrário, elevando a probabilidade em 3,93 p.p., enquanto no caso da transição para o superior completo a elevação seria de 5,54 p.p.. A transição da categoria-base para as situações completo e médio incompleto elevaria a probabilidade em 6,92 p.p. de o jovem apenas estudar; se a transição for para os níveis de ensino mais altos, os efeitos se invertem, decrescendo, respectivamente, em 4,03 p.p. e 3,04 p.p. a probabilidade predita de os jovens estarem nesse estrato.

Os coeficientes das variáveis dummies na análise da influência da estrutura da distribuição da renda domiciliar líquida na escolha dos jovens indicaram que a transição do primeiro décimo da distribuição utilizado como base para os demais décimos teria como efeito a redução da probabilidade de os jovens estarem em situação de vulnerabilidade, sem estudar e sem trabalhar. Esse decréscimo na transição para o segundo décimo seria de 4,02 p.p., chegando à redução de 16,57 p.p. na transição para o décimo superior da distribuição. Entretanto, elevaria a probabilidade de os jovens conciliarem o estudo com o trabalho, na transição para o segundo décimo em 1,76 p.p. e para o décimo superior em 18,52 p.p. É interessante destacar que os efeitos esperados, como a elevação da probabilidade de os jovens apenas estudarem e a redução de apenas trabalharem, na hipótese do aumento da renda líquida per capita domiciliar, só se confirmaram na transição da situação-base para o décimo superior da distribuição. Nas demais transições, os efeitos são inversos, ou seja, partindo do primeiro décimo para o sétimo, a probabilidade de os jovens apenas trabalharem aumentaria em 14,48 p.p. e a de apenas estudarem reduziria em 8,16 p.p. 
O comportamento descrito anteriormente, pode ser explicado, em termos, por dois motivos. O primeiro refere-se ao baixo rendimento da renda per capita líquida dos domicílios, em que, como foi já descrito, apenas a partir do oitavo decis, foram observados rendimentos acima do salário-mínimo. O segundo motivo refere-se à conjuntura econômica, no período da coleta dos dados da pesquisa, mais precisamente agosto de 2010, quando se observaram alto crescimento econômico e aumento na remuneração dos rendimentos do trabalho, principalmente no setor de serviços. Esses dois fatores tiveram como efeito o estímulo à entrada dos jovens no mercado de trabalho, acompanhada ou não dos estudos, com exceção, como já descrito, apenas dos jovens mais ricos, com renda domiciliar no último décimo da distribuição.

Para analisar a influência do território, utilizaram-se as dummies cidade rural, cidade pequena, cidade média e cidade grande, tomando como base a região rural. A transição de um jovem da região rural para as cidades reduziria as probabilidades preditas de ele se encontrar em uma situação de vulnerabilidade, não estudando nem trabalhando, e também na situação de não estudar e apenas trabalhar. Em contrapartida, essa transição elevaria a probabilidade de os jovens estudarem, conciliando ou não os estudos com o trabalho. Essa transição, segundo os coeficientes, seria mais intensa quando o destino dos jovens fosse as cidades mais urbanizadas. No caso da transição para a cidade grande, a probabilidade de os jovens se encontrarem em situação de vulnerabilidade ou apenas trabalhando decresceria, respectivamente, em 1,81p.p. e 8,8 p.p. e, em contrapartida, elevaria a probabilidade de apenas estudarem em 7,97 p.p. e conciliarem os estudos com o trabalho em 2,74 p.p.. Esse comportamento pode ser explicado pelo fato de que, na região rural, em comparação com as cidades, observa-se infraestrutura escolar precária, o que pode reforçar, juntamente com o trabalho agrícola familiar, o abandono prematuro à escola pelos jovens.

Finalmente, para analisar o efeito da posição dos jovens nos domicílios, considerando as características de gênero, utilizaram-se as dummies responsável pelo domicílio, cônjuge e filho. A transição da categoria-base, considerando todas as demais posições, para a situação jovem homem responsável pelo domicílio, reduziria a probabilidade predita de não trabalhar nem estudar em 16,99 p.p. e apenas estudar em 10,35 p.p.; em contrapartida, elevaria a probabilidade em apenas trabalhar em 25,73 p.p. e conciliar os estudos com o trabalho em 1,6 p.p.. É interessante ressaltar que se a transição for para jovem mulher responsável pelo domicílio os efeitos seriam inversos, ou seja, aumento da probabilidade de não trabalhar nem estudar em 4,68 p.p. e apenas estudar em 1,69 p.p. e redução da probabilidade de apenas trabalhar em 6,3 p.p.. A transição da variável-base para a situação homem cônjuge apresenta forte impacto na probabilidade de os jovens apenas trabalharem, aumentando em 34,01 p.p. e reduzindo a probabilidade de não trabalharem nem estudarem, apenas estudarem e conciliarem os estudos com o trabalho em, respectivamente, 9,3 p.p., 8,76 p.p. e 9,93 p.p.. A transição para mulher cônjuge teria também efeito contrário ao do homem, elevando em 28,05 p.p. a probabilidade de as jovens nessa condição não estudarem nem trabalharem e reduzindo a probabilidade de apenas trabalharem, apenas estu- 
darem e conciliarem os estudos com o trabalho em, respectivamente, 9,3 p.p., 8,76 p.p. e 9,93 p.p..

No caso da transição da situação-base para a posição do jovem filho no domicílio, condição essa, como era de se esperar, majoritária em relação às demais posições, no caso do sexo masculino, reduz-se a probabilidade de não estudar nem trabalhar e não estudar e apenas trabalhar em, respectivamente, 6,5 p.p. e 3,7 p.p.. Em contrapartida, aumenta a probabilidade em apenas estudar em 5,84 p.p. e conciliar os estudos com o trabalho em 4,38 p.p.. De forma similar, quando a transição se dá para as filhas, observa-se também a redução da probabilidade de não estudarem e trabalharem em 19,9 p.p. e, por sua vez, o aumento de apenas estudarem e conciliarem os estudos com o trabalho em, respectivamente, 15,41 p.p. e 3,13 p.p.. Nessa transição, observa-se também um pequeno aumento de 1,38 p.p. na probabilidade de as filhas não estudarem nem trabalharem.

Os resultados das estimações descritos acima, de forma geral, estão de acordo com importantes estudos do tema realizados para o Brasil para o mesmo período da presente pesquisa. Tillmann e Comim (2016), a partir dos dados da PNAD de 2011 e utilizando o conceito mais amplo de trabalho, para captar as diferenças das decisões de gênero quanto às ocupações domésticas, demonstraram que as condições domiciliares e a educação dos pais influenciaram a probabilidade de os jovens estudarem. Por outro lado, ser mulher, não branca, residente no meio rural e casada elevariam a probabilidade de não estudarem. Monteiro (2013), utilizando o conceito mais restrito de trabalho, analisa, para o período de 2001 a 2011, a partir dos dados da PNAD, a evolução e os determinantes dos jovens na situação nem-nem no Brasil. O estudo demonstrou que a condição nem-nem é mais marcante nos jovens de baixa renda, pouca escolaridade e mulheres, especialmente as com filhos. Entretanto, a autora ressalta que, no período, a participação dos homens com baixa educação aumentou neste grupo. E, finalmente, Costa e Ulyssea (2014) demonstram, entre 1992 a 2012, uma tendência de queda na proporção dos jovens nem-nem no Brasil, sendo que, no período entre 2009 e 2012, observou-se reversão dessa tendência de queda. Os autores demonstraram que a probabilidade de ser nem-nem está fortemente relacionada com o jovem ter baixa educação, reduzida renda domiciliar, ser mulher e ter filho e residir na região rural.

\subsection{Simulação da influência da estrutura da distribuição da renda per capita domiciliar liquida}

A estimação dos efeitos marginais evidenciou a forte influência das variáveis que representam as características socioeconômicas e territoriais dos jovens na escolha entre trabalho e estudo em Minas Gerais. Entretanto, como foi explicitado na metodologia, os efeitos marginais apontam, considerando tudo mais constante, mudanças das probabilidades em relação ao ponto médio das variáveis explicativas contínuas e para as variáveis independentes qualitativas, a variação da probabilidade do aconte- 
cimento entre dois grupos considerados. Para aprofundar o estudo, considerando as diferenças territoriais e a posição do jovem no domicílio, foram simulados os efeitos da estrutura da distribuição da renda per capita domiciliar líquida para cada décimo da distribuição.

A Figura 1 apresenta as simulações do impacto da estrutura da distribuição da renda per capita líquida domiciliar na probabilidade predita de os jovens decidirem entre trabalho e estudo, considerando os diferentes territórios. Os gráficos 1.A e 1.D demonstram, respectivamente, que, para todos os territórios, a transição dos jovens para os décimos superiores da distribuição reduz significativamente a probabilidade de estarem na situação de vulnerabilidade, nem estudando e nem trabalhando (NENT), e eleva a probabilidade de conciliarem o estudo com o trabalho (ET).

Figura 1. Impacto dos décimos da renda per capita domiciliar sobre a probabilidade de os jovens decidirem entre trabalho e estudo, considerando os diferentes territórios

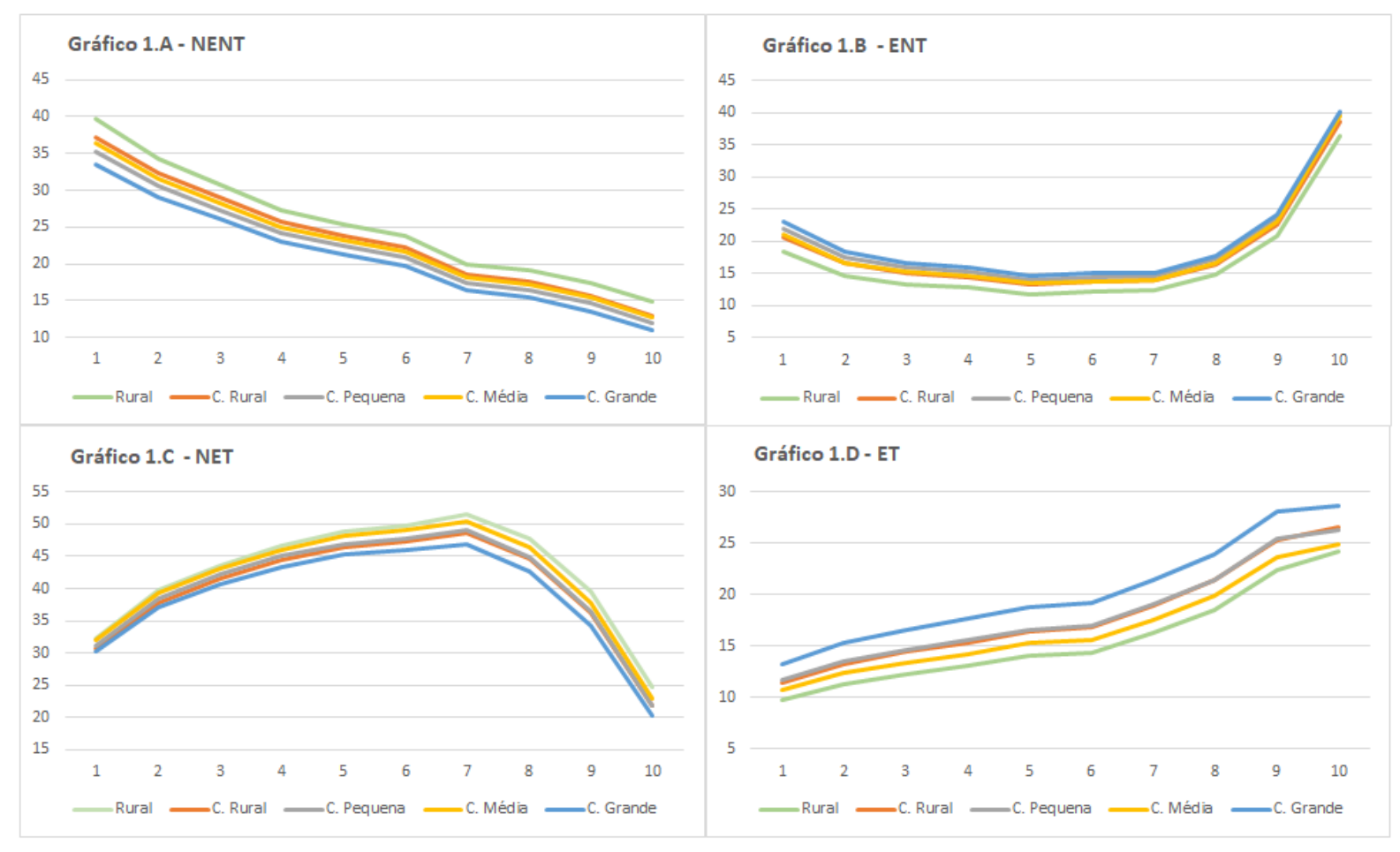

Elaboração própria a partir dos dados do Censo de 2010.

No caso da situação em que o jovem apenas estuda (ENT), descrita no gráfico 1.B, a transição do primeiro para o terceiro décimo da renda provoca pequena redução na probabilidade; entre o terceiro e o sétimo décimo, a probabilidade não se altera e, a partir do sétimo décimo, observa-se, para todos os territórios, forte elevação, passando em torno de $15 \%$ para $40 \%$ da probabilidade predita. Finalmente, ao contrário do esperado, a elevação da renda do primeiro décimo da distribuição para o sétimo, como pode ser observado no gráfico 1.C, eleva a probabilidade de os jovens apenas 
trabalharem (NET), reduzindo consideravelmente apenas a partir do sétimo décimo. Esse comportamento, como já foi ressaltado, pode estar relacionado com o baixo nível da renda per capita dos domicílios e com o mercado de trabalho aquecido, incentivando o ingresso dos jovens no mercado de trabalho e o abandono prematuro dos estudos.

As simulações da renda per capita considerando a posição dos jovens no domicílio na condição de filhos, enteados e netos, levando em conta as diferenças de gênero descritas na Figura 2, apresentam as mesmas tendências verificadas para os territórios, porém demonstrando fortes diferenças entre as probabilidades preditas entre os gêneros. As transições para os décimos superiores, como demonstrado no gráfico 2.A da Figura 2, reduzem a probabilidade de os filhos, enteados e netos estarem em situação de vulnerabilidade, nem estudando nem trabalhando (NENT). Entretanto, em todos os décimos, a probabilidade predita de as mulheres estarem nessa situação de vulnerabilidade é superior à dos homens.

Figura 2. Impacto dos décimos da renda per capita domiciliar sobre a probabilidade de os jovens na condição de filhos, enteados e netos decidirem entre trabalho e estudo, considerando o sexo

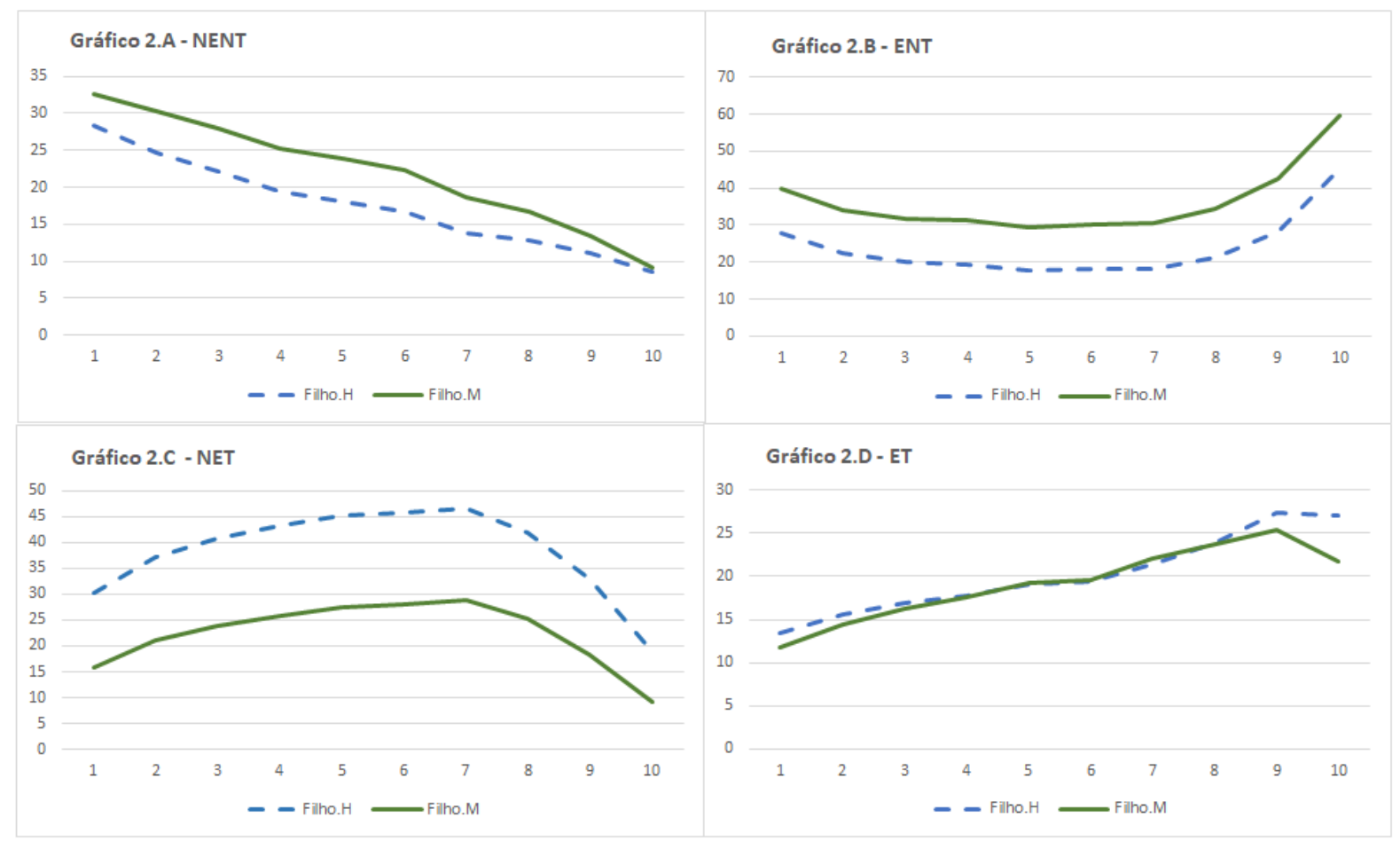

Elaboração própria a partir dos dados do Censo de 2010.

No caso da situação de apenas estudar (ENT), demonstrada no gráfico 2.B, a influência da renda ocorre apenas a partir do sétimo décimo, elevando a probabilidade, sendo que em todos os décimos a probabilidade de as mulheres apenas estudarem é superior à dos homens. Na situação de apenas trabalhar (NET), gráfico 2.C, a transi- 
ção até o sétimo décimo eleva a probabilidade e, a partir desse ponto, a reduz. Neste caso, em todos os décimos as probabilidades de os homens apenas trabalharem superam consideravelmente às das mulheres. Finalmente, de forma semelhante, a transição para os décimos superiores aumenta a probabilidade de os homens e as mulheres conciliarem os estudos com o trabalho (ET), descrita no gráfico 2.D, à exceção do décimo superior, em que se observa pequeno decréscimo dessa probabilidade para as mulheres.

Em síntese, as simulações evidenciam que a estrutura da distribuição da renda domiciliar per capita líquida no estado, caracterizada pelos baixos rendimentos e pela alta concentração, condiciona fortemente a influência das características socioeconômicas e territoriais na decisão dos jovens entre trabalhar e estudar.

Ao comparar, a título de exemplo, as probabilidades preditas das decisões dos jovens no território rural, com os décimos inferior e superior da distribuição, constatase a dimensão da desigualdade de renda no estado. O jovem com renda no primeiro décimo teria as seguintes probabilidades preditas: 39,6\%, estar em situação de vulnerabilidade, nem estudando nem trabalhando; $32,3 \%$ apenas trabalhando; $18,3 \%$ apenas estudando e 9,8\% conciliando os estudos com o trabalho. Se esse jovem estivesse no décimo superior, as probabilidades seriam bastante distintas e favoráveis à escolha prioritariamente para os estudos, assumindo os seguintes valores: $36,4 \%$ de probabilidade de apenas estudar, $24,2 \%$ de conciliar os estudos com o trabalho, $24,6 \%$ de apenas trabalhar e 14,8\% de estar na situação nem-nem.

\section{Conclusões}

O artigo, ao assumir a pressuposição da teoria do capital humano, que enfatiza que as decisões da família, condicionadas por características socioeconômicas, demográficas e territoriais, têm papel fundamental nas escolhas dos jovens e, como consequência, no seu futuro, buscou estimar, pelo modelo logit multinomial, a influência dos fatores internos e externos dos domicílios sobre a probabilidade da decisão dos jovens entre as atividades de estudo e trabalho no estado de Minas Gerais, em 2010.

Em síntese, os resultados das estimações, compatíveis com a literatura latinoamericana e brasileira, evidenciaram que, no estado, a transição dos jovens para a vida adulta, quando vislumbram sua autonomia diante dos seus familiares, por meio do ganho de capital humano e do acesso ao mercado de trabalho, é marcada pela desigualdade de oportunidades. Os jovens residentes nos territórios rurais, em relação aos residentes nas cidades, apresentaram maiores probabilidades de se verem em situação de vulnerabilidade, não estudando nem trabalhando, e de abandonarem os estudos precocemente e dedicarem o seu tempo exclusivamente ao trabalho. Os jovens brancos, em relação aos das demais raças, apresentaram maior probabilidade de estudarem ou conciliarem os estudos com o trabalho. Os jovens na condição de filhos, enteados e netos nos domicílios, no caso das mulheres, apresentaram maior 
probabilidade de estudarem e, no caso dos homens, apenas trabalharem.

Deve-se ressaltar que todas essas relações descritas foram condicionadas pela estrutura desigual da distribuição da renda domiciliar líquida no estado. Os jovens dos décimos superiores da distribuição, em relação aos demais, estudam mais, protelam a entrada no mercado de trabalho e, quando entram, obtêm os melhores postos de trabalho. Melhor explicando, observa-se o ciclo vicioso da desigualdade em nossa sociedade, em que as diferenças de oportunidades na transição dos jovens para a vida adulta, condicionadas pelas características individuais, territoriais e dos domicílios, irão, em certa medida, determinar a desigualdade no futuro. Para reverter ou ao menos amenizar esse ciclo vicioso, torna-se necessária maior atenção por parte das políticas públicas, voltadas principalmente para os jovens de baixa renda e residentes nas regiões rurais e cidades pequenas, no intuito de reduzir a proporção de jovens na condição nem-nem. O investimento nos jovens, segundo Novella et al. (2018), não promove benefícios apenas para esse grupo da população, mas trata-se de condição fundamental para viabilizar o desenvolvimento econômico, a coesão e o bem estar social.

A título de recomendação para futuras pesquisas, seria importante atualizar o estudo para a atual conjuntura econômica do estado de Minas Gerais e do país, em que, diferentemente de 2010, observam-se crise no mercado de trabalho, reversão das políticas públicas de seguridade social e queda na oferta de vagas no ensino, em todos os níveis da educação. Para tanto, resta aguardar a elaboração e publicação do Censo Demográfico de 2020 para a atualização desta pesquisa.

\section{Referências}

Alcázar, L., Rendòn, S., e Wachtenheim, E. (2002). Working and Studying in Rural Latin America: critical decisions of adolescence. Inter-American Development Bank Research, (Network Working Papers \#R-469).

Araújo, A. A. (2010). Tese de Doutorado. O programa Bolsa Família e o trabalho infantil no Brasil. Tese de doutorado - Programa de Pós-Graduação em Economia Aplicada. Universidade Federal de Viçosa, Viçosa.

Becker, G. S. (1993). Human capital: a theoretical and Empirical Analysis, with Special Reference to Education. Chicago: University of Chicago.

Bertrand, A. L. (1973). Sociologia Rural: uma análise da vida rural contemporânea. c.

Camarano, A. A. e Kanso, S. (2012). O que estão fazendo os jovens que não estudam, não trabalham e não procuram trabalho?. Instituto de Pesquisa Econômica Aplicada. (Boletim de mercado de trabalho: conjuntura e análise, n.53).

Camarano, A. A., Mello, J. L., Pasinato, M. T., e Kanso, S. (2004). Tese de Doutorado. Caminhos para a vida adulta: as múltiplas trajetórias dos jovens brasileiros. Instituto de Pesquisa Econômica Aplicada. (Texto para discussão, n. 1038). 
Casal, J., Masjoan, J., e Planas, J. (1988). Elementos para un análisis sociológico de la transición a la vida adulta. Politica y Sociedad, Madri, Espanha, Universidad Complutense de Madrid, n. 1, p. 97-104.

Corseuil, C. H., Santos, D. D., e Foguel, M. N. (2001). Tese de Doutorado. Decisões críticas em idades críticas: a escolha dos jovens entre estudo e trabalho no Brasil e em outros países da América Latina. Instituto de Pesquisa Econômica Aplicada. (Texto para discussão, núm. 797).

Costa, J. S., Becker, K. L., e Pavão, A. R. (2013). Influência da renda domiciliar per capita na alocação do tempo dos jovens no Brasil. Revista de Economia, v. 39, n. 1, p. 7-24. DOI: http://dx.doi.org/10.5380/re.v39i1.

Costa, J. S. M. e Ulyssea, G. (2014). O fenômeno dos jovens nem-nem. In: Autoria do livro. CORSEUIL, C. H and BOTELHO, R. U. (Orgs) Desafios à trajetória profissional dos jovens brasileiros. Rio de Janeiro: IPEA, p. 115-140.

Escolano, A. J. M. e Pazello, E. T. (2014). rabalhar e ou continuar estudando? As decisões dos jovens que se matriculam no último ano do ensino médio - uma análise a partir da PME. In: Anais $42^{\circ}$ Encontro Nacional de Economia, Associação Nacional de Pós-graduação em Economia. Natal, RN.

Fernandes, M. (2008). Tese de Doutorado. Estimação da oferta de trabalho com modelos coletivos: uma aplicação para o Brasil. Dissertação de Mestrado em Economia Universidade Estadual de São Paulo, Ribeirão Preto, Brasil, Data de Defesa.

Greene, W. (2012). Econometric analysis. New York: Prentice Hall.

Grossi, M. E. e Silva, G. (2002). O novo rural: Uma abordagem ilustrada. Londrina: Instituto Agronômico do Paraná.

IBGE - Instituto Brasileiro de Geografia e Estatística (2012). Censo Demográfico de 2010. Brasília, IBGE.

IBGE - Instituto Brasileiro de Geografia e Estatística (2017). Sintese de indicadores sociais: uma análise das condições de vida da população brasileira. Estudos e Pesquisas: Informação Demográfica e Socioeconômica, n. 37, Rio de Janeiro, IBGE.

Maia, A. G. e Buainain, A. M. (2015). O novo mapa da população rural brasileira. Revista Franco-Brasileira, n. 25, p. 1-26.

Monteiro, J. (2013). Tese de Doutorado. Quem são os jovens nem-nem? Uma análise sobre os jovens que não estudam e não participam do mercado de trabalho. Fundação Getúlio Vargas, Instituto Brasileiro de Economia. (Texto para Discussão, n. 34).

Ney, M. G. e Hoffmann, R. (2009). Educação, concentração fundiária e desigualdade de rendimento no meio rural. Revista de Economia e Sociologia Rural, v. 47, n. 1, p. 147-182. 
Novella, R., Repeto, A., Robino, A. C., e Rucci, G. (2018). Millennials en América Latina y el Caribe: ¿trabajar o estudiar?. Banco Interamericano de Desarrollo. Disponivel em: http:// creativecommons.org/licenses/by-nc-nd/3.0/igo/legalcode).

Oliveira, F. A. e Siqueira, W. B. (2010). As muitas Minas: ensaios sobre a economia mineira. Belo Horizonte: Conselho Regional de Economia de Minas Gerais.

Oliveira, P. R., Scorzafave, L. G., e Pazello, E. T. (2009). Desemprego e inatividade nas metrópoles brasileiras: as diferenças entre homens e mulheres. Nova Economia, n. 19, v. 2, p. 291-324.

Reis, D. S. (2006). O rural e urbano no Brasil. In: Anais do XV Encontro Nacional de Estudos Populacionais, Associação Brasileira de Estudos Populacionais, Caxambú, MG.

Sorokin, P. A., Zimmermam, C. C., e Galpin, C. J. (1929). Diferenças Fundamentais entre o mundo rural e urbano. MARTINS, J. S. (Orgs) Introdução Crítica à Sociologia Rural. São Paulo: Hucitec, p. 198-224.

Sposito, M. P. (2000). Considerações em torno do conhecimento sobre juventude na área da educação. In: SPOSITO, M. P. (Orgs) Estado do Conhecimento: Juventude e Escolarização. São Paulo: Ação Educativa, p. 6-34.

Tillmann, E. e Comim, F. (2016). Os determinantes das decisões entre estudo e trabalho dos jovens no Brasil e a geração nem-nem. Pesquisa e Planejamento Econômico, v.46, n.2, p. 47-78.

Tomás, M. C. (2006). Renda de não trabalho e alocação do tempo de crianças e jovens: uma análise para 2003. In: Anais do XV Encontro Nacional de Estudos Populacionais, Associação Brasileira de Estudos Populacionais, Caxambú, MG.

Veiga, J. E. (2002). Cidades Imaginárias: O Brasil é menos urbano do que se calcula. Campinas: Editora Autores Associados.

๔Ev Este artigo está licenciado com uma CC BY 4.0 license. 


\section{Appendix}

Neste artigo, utilizou-se como fonte a amostra de pessoas dos microdados do censo demográfico de 2010 (IBGE - Instituto Brasileiro de Geografia e Estatística, 2012). Para obtermos a amostra dos jovens, a partir da variável V6036 (idade calculada em anos), definiu-se os indivíduos com idade entre 15 e 25 anos. Excluindo deste grupo os indivíduos declarados índios e raça ignorada, variável V0606 (cor ou raça), e aqueles na condição de "indivíduos em domicílio coletivo" da variável V0502 (relação de parentesco e convivência).

Após a definição da amostra dos jovens, através das variáveis V6920 (situação de ocupação) e V0628 (frequenta escola ou creche), foi possivel identificar as escolhas dos jovens entre estudo e trabalho. O Guadro Al detalha os códigos das variáveis dos microdados e os procedimentos utilizados na definição dos regressores do modelo econométrico. Para transformar a amostra no universo da população, utilizou-se a variável V0010 (peso).

Quadro A1. Códigos dos microdados e definição das variáveis

\begin{tabular}{|c|c|}
\hline Variável & Códigos dos microdados utilizados na definição dos regressores \\
\hline Idade & V6036 (idade calculada em anos) \\
\hline Raça & V0606 (cor ou raça) \\
\hline Número de pessoas & $\begin{array}{l}\text { V0504 (ordem da pessoa) atribui um número de ordem sequencial para cada morador, } \\
\text { tornando-se possível identificar o número total de pessoas residentes no domicílio. }\end{array}$ \\
\hline Instrução & $\begin{array}{l}\text { V6400 (nível de instrução), desconsiderando os indivíduos com nível indeterminado. } \\
\text { A renda domiciliar per capita líquida do jovem subtrai da renda per capita domiciliar, }\end{array}$ \\
\hline $\begin{array}{l}\text { Renda domiciliar } \\
\text { per capita líquida }\end{array}$ & $\begin{array}{l}\text { V6531 (rendimento domiciliar per capita), os seus rendimentos monetários, obtidos } \\
\text { através das variáveis V6525 (rendimentos em todos os trabalhos) e }\end{array}$ \\
\hline & V0504 (ordem da pessoa) para identificar o número de pessoas no domicílio. \\
\hline Território & $\begin{array}{l}\text { V1006 (situação do domicílio), os indivíduos residentes nas áreas rurais dos municípios } \\
\text { formam o territorial rural. Os residentes nas áreas urbanas, segundo a população total, } \\
\text { V0002 (municípios), e a densidade demográfica, PNUD (2013), formam as cidades rural, } \\
\text { pequena, média e grande. }\end{array}$ \\
\hline $\begin{array}{l}\text { Responsável pelo } \\
\text { domicílio }\end{array}$ & $\begin{array}{l}\text { V0502 (relação de parentesco ou de convivência com a pessoa responsável pelo domicílio) } \\
\text { indica se o jovem é responsável pelo domicílio e V0601 (sexo) o seu sexo. }\end{array}$ \\
\hline Cônjuge & $\begin{array}{l}\text { V0502 (relação de parentesco ou de convivência com a pessoa responsável pelo domicílio) } \\
\text { indica se o jovem é cônjuge no domicílio e V0601 (sexo) o seu sexo. }\end{array}$ \\
\hline $\begin{array}{l}\text { Filhos, enteados } \\
\text { e netos }\end{array}$ & $\begin{array}{l}\text { V0502 (relação de parentesco ou de convivência com a pessoa responsável pelo domicílio) } \\
\text { indica se o jovem é filho, enteado ou neto no domicílio e V0601 (sexo) o seu sexo. }\end{array}$ \\
\hline
\end{tabular}

Fonte: Elaboração própria a partir dos dados do Censo de 2010. 